\title{
Hyperkalemia a Therapeutic Callenge for Physicians Treating Patients of Type 1 and Type 2 Diabetes Mellitus in Saudi Arabia
}

\author{
Abdul Rahman Al-Ajlan*
}

\author{
Clinical Biochemistry, Dean, Riyadh College of Health Sciences, (Men), King Saud University, Kingdom of Saudi \\ Arabia
}

\begin{abstract}
The objective of this study is to determine the level of hyperkalemia in Saudi patients of type 1 and type 2 diabetes mellitus.

In the present study, 362 male and female known diabetic patients of type 1 and type 2 and 158 non diabetic control subjects visiting Al Iman and Prince Salman hospitals of Riyadh were studied from November 2004 to July 2006. 12.6\% type 1 and $18.5 \%$ of type 2 diabetics in our study had some sort of impaired renal functions, but none of them had shown signs of acute renal failure. Only a small percentage of 5\% patients in type 2 diabetes group 3 were on ACE inhibitors. The diabetics were subdivided on the basis of their fasting plasma glucose levels (FPG) in three groups, group 1( 7.1 -10.0 ) group2 (10.1 -20.0) and group3 ( >20.0) $\mathrm{mmol} / \mathrm{L}$ and their serum potassium levels were estimated.

Hypekalemia was not detected in the group 1 diabetics of type1 and females of type2. The group 2 diabetics of type 1 and type 2 showed serum potassium levels of $5.9 \pm 1.1$ and $7.2 \pm 1.4 \mathrm{mmol} / \mathrm{L}(\mathrm{P}<0.001)$. The serum potassium levels among the group 3 diabetics with a FPG of $>20 \mathrm{mmol} / \mathrm{L}$ were $6.8 \pm 1.2(\mathrm{r}=0.56)$ and $8.1 \pm 1.7 \mathrm{mmol} / \mathrm{L}(\mathrm{r}=0.68) \mathrm{P}<0.05$.

It was observed that there is a strong association between hyperglycemia and hyperkalemia, even in the absence of dialysis or RAAS therapy, in Saudi diabetics. The elderly uncontrolled diabetics are at a higher risk of hyperkalemia. Hyperkalemia in uncontrolled diabetics can lead to kidney and liver damage and cardiac arrest. The physicians while prescribing ACE inhibitors to diabetics must take precautions to avoid complications of hyperkalemia, leading to cardiac emergencies.
\end{abstract}

Keywords: Diabetes Mellitus, Hyperkalemia, Saudi Arabia.

\section{INTRODUCTION}

Potassium is the most abundant cation in the body. $98 \%$ of the total $4000 \mathrm{mmol}$ is in the intracellular fluid compartment, only $60 \mathrm{mmol}$ being in the extracellular fluid of an adult. The kidneys regulate long term balance of potassium [1]. Cellular uptake of potassium is regulated by insulin, acid base status aldosterone and adrenergic activity. Hyperkalemia is caused by redistribution of potassium from the intracellular to the extracellular fluid compartment due to the factors leading to impaired cellular uptake, like insulin insufficiency [2]. Decreased renal excretion adds to further retention of potassium [2, 3].

Hyperkalemia is a life threatening emergency and warrants immediate treatment because of its deleterious cardiac consequences [4]. In general physiological and pathological changes that occur in patients as they grow older may result in distal renal tubular dysfunction, as well as decreased level of plasma aldosteron. Such alterations result in a tendency toward hyperkalemia [5-7]. Abnormalities of potassium homeostasis in diabetes are probably related to insulin and mineralcorticoid deficiency [8]. Chronic hyperkalemia in elderly diabetics is most often

*Address correspondence to this author at the Dean, Riyadh College of Health Sciences (Men), King Saud University, P. O. Box \# 22637, Riyadh \# 11416, Kingdom of Saudi Arabia; Tel: Off. 014484964 Fax: 01-4481033; E-Mail: aalaj1@hotmail.com attributable to hyporeninemic hypoaldosteronism [9]. In the diabetic with ketoacidosis hyperkalemia in the face of potassium depletion may be attributed to reduced renal function, acidosis and release of potassium from cells due to glycogenolysis [9].

Generally diabetes is considered as an independent cause of hyperkalemia [10]. Studies have shown that hyperglycemia alone and not insulin or epinephrine or glucagon is a direct determinant of plasma potassium [1113]. The hyperkalemia may be intermittent or persistent [14, $15]$.

A paradoxical rise in potassium concentration has been found in diabetic patients, after infusion of glucose leading to hyperglycemia [16-17]. Insulin itself plays an important role in potassium homeostasis even in the absence of overt mineralocorticoid deficiency [18] Hyperkalemia even in the absence of renal failure have been reported earlier, though the exact mechanism leading to hyperkalemia could not be ascertained [19].

Physicians treating patients with diabetes should be aware of the dangers of precipitating life threatening hyperkalemia whenever prescribing for their patients. Dangerous hyperkalemia during use of ACE inhibitors and potassium-sparing diuretics have been reported in diabetic patients [19-22]. 
Our objective is to draw attention to the fact that hyperglycemia induces severe hyperkalemia especially in the setting of insulin absence or reduced insulin responsiveness. The risk factors for hyperkalemia include advanced age, significant prematurity, and presence of renal failure, diabetes mellitus, and heart failure. Polypharmacy, particularly the use of potassium supplements and potassium-sparing diuretics, in patients underlying renal insufficiency contributed to hyperkalemia in almost one half of the cases [19-23]. The data are not available about the incidence of hyperkalemia in diabetics in Saudi Arabia. Our study is first of its kind in this region.

\section{MATERIALS \& METHODS}

In this study 362 diabetic patients and 158 control nondiabetics were studied from September 2003 to August 2005 at Al Iman general hospital and prince Salman hospitals of Riyadh, Saudi Arabia.

The average age of the male and female control subjects was $19.5(6-25)$ years and $18(5-24)$ years while the mean age of type 1 male diabetics was 17 ( $4-25)$ years and female was 18 ( 5-23) years of age. Similarly the male and female control subjects included in the study of Type 2 diabetes were 45 ( 26-75) and 46 ( 26- 79) years of age. The average age of the diabetic type 2 male and female patients were 47 (32-80) and 45 ( $35-72$ ) years respectively.

The patients were classified in type 1 and type 2 diabetes mellitus on the basis of classification of diabetes of 1997 given by the "International expert committee on the diagnosis and classification of diabetes mellitus" [21]. We found that 119 patients were diagnosed as Type 1 and 243 as type 2 diabetes mellitus .

The type 1 and type 2 diabetics were subdivided in three study groups based on their fasting plasma glucose (FPG) levels as Group -1 (7.1- $10 \mathrm{mmol} / \mathrm{L}$ ), group-2 ( $10.1-20$ $\mathrm{mmol} / \mathrm{L}$ ) and Group $-3(>20 \mathrm{mmol} / \mathrm{L}$ ). The non diabeic control group having a FPG level of $<7.0 \mathrm{mmol} / \mathrm{L}$ and corresponding to the age group of less than 25 years and more than 25 years for type 1 and type 2 diabetes mellitus were selected randomly from the out patients of the hospitals at study.
The serum potassium levels of $>5.0 \mathrm{mmol} / \mathrm{L}$ was considered as hyperkalemia [14].

In each group of normal control subjects and diabetic patients, a blood sample of $10 \mathrm{ml}$ was withdrawn after twelve hours of fasting in fluoride and plain vials, and subjected to measurement of plasma glucose level and serum potassium ion. Samples were stored at $4{ }^{\circ} \mathrm{C}$ for not more than 2 hours. The plasma was carefully separated by centrifugation at $3000 \mathrm{rpm}$ for 10 minutes. Fasting plasma glucose was measured by glucoxidase peroxidase (God Pod) method on Dade- Behring ,Dimension AR analyzer. The estimation of serum potassium was carried out by spectrophotometry.

All the subjects under study had undergone a thorough examination and laboratory tests for renal functions. Significantly none of our subjects were in acute renal failure or on any form of dialysis. The patients with or without signs of renal impairment were categorized separately.

\section{Statistical Analysis}

Comparison of continuous variables was carried out by student $t$ test. The value of $p<0.05$ for different variables was considered significant. Analysis of variance was used to test differences between the potassium ion concentration and the duration of hyperkalemia. Pearson's correlation coefficient was applied to correlate the levels of FPG with serum potassium.

\section{OBSERVATIONS}

It was observed that mostly older patients with a mean age of $60 \mathrm{had}$ FPG level of $>20 \mathrm{mmol} / \mathrm{L}$ and fell in the group 3 .The females with type 2 diabetes in group 2 with FPG level between 10.1 and $20.0 \mathrm{mmol} / \mathrm{L}$ were the oldest with an average age of 58 years.

There was no significant difference in the mean FPG levels of male and female control subjects studied with type 1 and type 2 diabetes mellitus patients. The FPG level ranged between 4.05 to $5.03 \mathrm{mmol} / \mathrm{L}$.

9(7.5\%) patients of type1 and $15(6.1 \%)$ patients of type 2 had developed ketoacidosis during their course of treatment.

Table 1. Showing Number and Percentage of Cases of Hyperkalemia in Each Study Group of Type 1 Diabetes Mellitus

\begin{tabular}{|c|c|c|c|c|c|}
\hline \multirow[t]{2}{*}{ Study Groups } & \multirow[t]{2}{*}{$\begin{array}{c}\text { FPG Levels } \\
\mathrm{mmol} / \mathrm{L}\end{array}$} & \multicolumn{2}{|c|}{$\begin{array}{l}\text { S. Potassium levels } \\
\text { ( Mean \& SD) mmol/L }\end{array}$} & \multirow{2}{*}{$\begin{array}{c}\text { Total number \& Percentage of cases of } \\
\text { hyperkalemia in both sexes }\end{array}$} & \multirow{2}{*}{$\begin{array}{c}\text { No. \& percentage of cases with no } \\
\text { signs of renal impairment } \\
-\end{array}$} \\
\hline & & $\begin{array}{c}M \\
(n=94)\end{array}$ & $\begin{array}{c}F \\
(n=61)\end{array}$ & & \\
\hline $\begin{array}{l}\text { Control } \\
(\mathrm{n}=36)\end{array}$ & $<7.0-7.0$ & $4.0 \pm 0.52$ & $3.9 \pm 0.11$ & - & - \\
\hline $\begin{array}{l}\text { Group } 1 \\
(n=27)\end{array}$ & $7.1-10$ & $4.7 \pm 1.01$ & $4.5 \pm 0.98$ & - & - \\
\hline $\begin{array}{l}\text { Group } 2 \\
(\mathrm{n}=74)\end{array}$ & $10-20$ & $5.9 \pm 1.1$ & $5.8 \pm 1.3$ & $5(6.7 \%)$ & $3(4.05 \%)$ \\
\hline $\begin{array}{c}\text { Group } 3 \\
(n=18)\end{array}$ & $>20$ & $6.8 \pm 1.2$ & $6.3 \pm 1.1$ & $2(11.1 \%)$ & $1(5.5 \%)$ \\
\hline
\end{tabular}

$\mathrm{n}=$ number, $\mathrm{FPG}=$ fasting plasma glucose, $\mathrm{SD}=$ standard deviation, $\mathrm{M}=$ male, $\mathrm{F}=$ female. 
The mean serum potassium level in the controls of type 2 diabetes was little higher ( $4.1 \pm 0.6$ vs $3.9 \pm 0.11 \mathrm{mmol} / \mathrm{L}$ ) than type 1 controls $(\mathrm{p}<0.05)$.

Table 1 shows the mean and SD of the levels of serum potassium in three study groups of type 1 diabetes mellitus patients, and also the number of cases of hyperkalemia 5 $(6.7 \%)$ in Group 2 and $2(11.1 \%)$ patients in group 3 were categorized as cases of hyperkalemia.. $3(4.05 \%)$ in group 2 and $1(5.5 \%)$ cases were those who had no signs of renal impairment.

Table 2 shows the mean and SD of the levels of serum potassium in the patients of three study groups of diabetes mellitus type 2 .

In type 2 diabetics mild, hyperkalemia was observed in 3 $(3.8 \%)$ males even in group 1 .In group 2 and group 3 the number of hyperkalemics were $20(15.5 \%)$ and $6(17.1 \%)$.

In type 2 diabetics all the cases of hyperkalemia in group 1 had some evidence of renal impairment, while in Group 2 and group $36(4.6 \%)$ and $3(8.5 \%)$ of cases showed no signs of renal impairment.

No significant sex bias was noticed in the serum potassium levels in the type 1 diabetes mellitus patients, while in type 2 diabetes the male patients in group 2 and 3 had higher levels of serum potassium.

The change in potassium concentration also correlated with the initial potassium level $(\mathrm{r}=0.771, \mathrm{P}=0.011)$ The most significant finding common to both type 1 and type 2 diabetes mellitus was a proportionate rise in the levels of serum potassium with the increasing levels of FPG. The highest levels of $8.1 \pm 1.7(\mathrm{r}=0.68, \mathrm{P}=0.014)$ of serum potassium was found in the males of group 3 ( > 20 FPG ) of type 2 diabetics. In the type 1 diabetes the marked rise in serum potassium level was observed in group 3 patients while in type 2 patients there was a noticeable rise even in the group 2.

Clinically significant association was observed with increasing age, level of hyperglycemia and hyperkalemia. $(\mathrm{P}=0.002)$

\section{DISCUSSION}

In this study which is first of its kind in Saudi Arabia, we had tried to find the incidence of hyperkalemia in type 1 and 2 diabetes mellitus patients. 362 diabetes mellitus patients of which, 119 were type 1 and 243 were type 2 and 158 healthy control subjects were included in the study. For classification of diabetes mellitus we have followed the established criteria of the International expert committee [24]. The cut off upper limit for fasting plasma glucose (FPG) level in normal controls was taken as $<7.0 \mathrm{mmol} / \mathrm{L}$.Hyperkalemia was considered in patients having a serum potassium level of $>$ $5.0 \mathrm{mmol} / \mathrm{L}[14]$.

The presence of hyperglycemia leads to a shift of water and potassium from the intracellular to the extracellular space. This shift of potassium is further enhanced in the presence of acidosis and insulinopenia [25]. Hyperkalemia is known to be relatively common in diabetic patients reflecting the role of insulin in potassium homeostasis. The unreported feature is the independent effect of diabetes in attenuating the early dip in serum potassium concentration and its later recovery. In these respects, patients with diabetes behaved remarkably like patients pretreated with $\beta$ Blockers, making sympathetic nerve dysfunction, the most plausible explanation for the effects on potassium [26].

Acute renal failure is a well known cause of hyperkalemia ,but studies have been carried out in the past where hyperkalemia has been detected in diabetics without signs of renal failure or impairment. We quote from Jarman et al. [19]. "This study shows that hyperkalemia is relatively common in unselected diabetic outpatients, even when there is no significant elevation of serum creatinine, and even in the absence of drugs known to elevate potassium levels." They further write that " It ( hyperkalemia) can not be attributed solely to renal impairment because hyperkalemia is usually associated only with advanced renal failure" G.C Viberti [18] has reported in 1978 that "At present one can only speculate upon mechanism of glucose induced hyperkalemia in insulin deprived diabetics with normal renal function". These earlier studies substantiate our findings that hyperkalemia is detected in diabetics even in the absence of

Table 2. Showing Number and Percentage of Cases of Hyperkalemia in Each Study Group of Type 2 Diabetes Mellitus

\begin{tabular}{|c|c|c|c|c|c|}
\hline \multirow[t]{2}{*}{ Study Groups } & \multirow[t]{2}{*}{$\begin{array}{c}\text { FPG Levels } \\
\text { mmol/L }\end{array}$} & \multicolumn{2}{|c|}{$\begin{array}{l}\text { S. Potassium levels } \\
\text { ( Mean \& SD) mmol/L }\end{array}$} & \multirow{2}{*}{$\begin{array}{c}\text { Total number \& Percentage of cases } \\
\text { of hyperkalemia in both sexes }\end{array}$} & \multirow{2}{*}{$\begin{array}{c}\text { No. \& percentage of cases with } \\
\text { no signs of renal impairment } \\
-\end{array}$} \\
\hline & & $\begin{array}{c}M \\
(n=215)\end{array}$ & $\begin{array}{c}F \\
(n=150)\end{array}$ & & \\
\hline $\begin{array}{l}\text { Control } \\
(\mathrm{n}=122)\end{array}$ & $<7.0-7.0$ & $4.3 \pm 0.8$ & $4.1 \pm 0.6$ & - & - \\
\hline $\begin{array}{c}\text { Group } 1 \\
(\mathrm{n}=78)\end{array}$ & $7.1-10$ & $5.5 \pm 1.4$ & $4.9 \pm 1.2$ & $3(3.8 \%)$ & - \\
\hline $\begin{array}{l}\text { Group } 2 \\
(\mathrm{n}=130)\end{array}$ & $10-20$ & $7.2 \pm 1.4$ & $6.6 \pm 1.05$ & $20(15.5 \%)$ & $6(4.6 \%)$ \\
\hline $\begin{array}{l}\text { Group } 3 \\
(\mathrm{n}=35)\end{array}$ & $>20$ & $8.1 \pm 1.7$ & $8.0 \pm 1.09$ & $6(17.1 \%)$ & $3(8.5 \%)$ \\
\hline
\end{tabular}

$\mathrm{n}=$ number, $\mathrm{FPG}=$ fasting plasma glucose, $\mathrm{SD}=$ standard deviation, $\mathrm{M}=$ male, $\mathrm{F}=$ female. 
renal impairment. As in our study we discovered $5.5 \%$ cases in group 3 of type 1 and $8.5 \%$ cases in type 2 of hyperkalemia who showed no signs of renal impairment [819].

The common occurrence of hyperkalemia in the elderly may be aggravated by the use of drugs that either further suppress renin and aldosteron, or interfere with distal tubular potassium excretion.

If such patients are given RAAS blockers the serum potassium increases to dangerously high level.

We conclude that there is an association between hyperglycemia and hyperkalemia in both types of diabetes mellitus of type 1 and type 2 with or without renal impairment [8-19], The exact mechanism of hyperkalemia in these cases requires indepth study. Though the patients on dialysis and RAAS blockers are the established causes of hyperkalemia [27], but other factors as medications of non steroidal anti inflammatory drugs and paradoxical hyperkalemia are to be considered in patients of diabetes mellitus [16]. In uncontrolled, elderly type 2 diabetics having a FPG level of $>20 \mathrm{mmol} / \mathrm{L}$, the hyperkalemia is marked, and any addition of ACE inhibitors in their treatment, may lead to cardiac emergencies [4].

Physicians while prescribing ACE inhibitors to their diabetic patients must be careful because a combination of uncontrolled hyperglycemia, use of ACE inhibitors may lead to severe hyperkalemia and may precipitate cardiac arrest [19-21].

\section{REFERENCES}

[1] Halperin, M.L.; Kamel, S. Potassium- Electrolyte quintet. Lancet, 1998, 352, 135-140.

[2] Brown, R.S. Potassium homeostasis and clinical implications. Am. J. Med., 1984, 77(5A), 3-10.

[3] Rodrriguez-Soriano, J. Potassium homeostasis and its disturbances in children. Pediatr. Nephrol., 1995, 9(3), 364-374.

[4] Kemper, M.J.; Harps, E.; Muller-Wiefel, D.E. Hyperkalemia: Therapeutic options in acute and chronic renal failure. Clin. Nephrol., 1996, 46(1), 67-69.

[5] Wlasmley, R.N.; White, G.H.; Cain, M.; McCarthy, P.C.; Booth, J. Hyperkalemia in the elderly. Clin. Chem., 1984, 30, 1409-1412.

[6] Michelis, M.F. Hyperkalemia in the elderly. Am. J. Kidney Dis., 1990, (4), 296-299.

[7] Williams, M.E. Endocrine crises. Hyperkalemia. Crit. Care Clin., 1991, 7(1), 155-174.
[8] Perez, G.O.; Lespier, L.; Knowles, R.; Oster, J.R.; Vaamonde, C.A. Potassium homeostasis in chronic diabetes mellitus. Arch. Intern. Med., 1997, 137(8), 1018-1022.

[9] Uribarri, J.; Oh, M.S.; Carroll, H.J. Hyperkalemia in diabetes mellitus. J. Diabet. Complications 1990, 4(1), 3-7.

[10] Jarman, P.R.; Mather, H.M. Diabetes may be independent risk factor for hyperkalemia. $B M J \mathbf{2 0 0 3}, 327(7418), 812$.

[11] Goldfarb, S.; Cox, M.; Singer, I. Acute hyperkalemia induced by hyperglycemia: Hormonal mechanism. Ann. Intern. Med., 1976, 84, 426-432.

[12] Rosetock, J.; Loizou, S.; Brajkovich, I. Effect of acute hyperglycemia on plasma potassium and aldosterone levels in type 2 diabetes. Diabetologica 1982, 22, 184-187.

[13] Ammon, R.; May, W.; Nightingale, S. Glucose induced hyperglycemia with normal aldosterone levels - studies in a patient with diabetes mellitus. Ann. Intern. Med., 1978, 89, 349-351.

[14] Popp, D.; Achtenberg, J.F.; Cryer, P.E. Hyperkalemia and hyperglycemic increments in plasma potassium in diabetes mellitus. Arch. Intern. Med., 1980, 140 (12), 1617-1621.

[15] Magnus, N.C.; Jackson, E. Intractable life-threatening hyperkalemia in a diabetic patient. Nephrol. Dial. Transplant., 2000, 15(1), 113-114.

[16] Goldfarb, S.; Strunk, B.; Singer, I.; Goldberg, M. Parodoxical glucose induced hyperkalemia- combined aldosterone-insulin deficiency. Am. J. Med., 1975, 59, 744-750.

[17] Cox, M.; Sterns, R.H.; Singer, I. The defense against hyperkalemia: The roles of insulin and aldosterone. N. Engl. J. Med., 1978, 299, 525-537.

[18] Viberti, G.C. Glucose induced hyperkalemia: A hazard for diabetics. Lancet, 1978, 1, 690-691.

[19] Jarman, P.R.; Kehley, A.M.; Mather, H.M. Hyperkalemia in diabetes: prevalence and associations. Postgrad. Med. J., 1995, 71, $551-552$.

[20] Segal, A. Hyperkalemia and inhibitors of the renin-angiotensin aldosterone system. N. Engl. J. Med., 2004, 351(23), 2450-2451.

[21] Palmar, B.F. Managing hyperkalemia caused by inhibitors of rennin-angiotensin system. N. Engl. J. Med., 2004, 351, 543-551.

[22] Odawara, M.; Asano, M.; Yamashita, K. Life threatening hyperkalemia caused by angiotensin - converting enzyme inhibitor and diuretics. Diabet. Med., 1997, 14, 169-170.

[23] Allon, M. Hyperkalemia in end stage renal disease; mechanism and management. J. Am. Soc. Nephrol., 1995, 6 (4), 1134-1142.

[24] Jennifer, M. Diagnosis and Classification of Diabetes Mellitus: New Criteria. Am. Fam. Physicians, 1998, 58, 1426- 1436.

[25] Lederer, E. Hyperkalemia. Available from: www.emedicine. com/med/topic1082.htm. 2003, pp. 1425-1428.

[26] Umpierrez, G.E.; Khajavi, M.; Kitabchi, A.E. Review: diabetic ketoacidosis and hyperglycemic hyperosmolar nonketotic syndrome. Am. J. Med. Sci., 1996, 311, 225 -233.

[27] Rao, M.V.; Bakris, G.L. Serum creatinine increases and RAAS blocker therapy: An Update. Medscape Nephrology, Chronic kidney disease expert column 2008, @ 2008 Medscape.

(C) Abdul Rahman Al-Ajlan; Licensee Bentham Open.

This is an open access article licensed under the terms of the Creative Commons Attribution Non-Commercial License (http://creativecommons.org/licenses/by-nc/3.0/) which permits unrestricted, non-commercial use, distribution and reproduction in any medium, provided the work is properly cited. 